УДК 681.121.4+681.121.8(035)

\title{
ИЗМЕРЕНИЕ РАСХОДА ВОЛОКНИСТЫХ СУСПЕНЗИЙ В ЦЕЛЛЮЛОЗНО-БУМАЖНОМ ПРОИЗВОДСТВЕ
}

\author{
() М.С. Лурье, А.С. Фролов" \\ Сибирский государственный технологический университет, пр. Мира, 82, \\ Красноярск, 660049 (Россия), e-mail: Frolov-a84@mail.ru
}

В работе исследуется оборудование для измерения расхода волокнистой суспензии. Предложен метод испытания погружных вихревых расходомеров, учитывающий как гидродинамику работающего в трубопроводе расходомера, так и свойства волокнистой суспензии (концентрация, степень помола, температура). Приведены математические соотношения, поясняющие работу испытательного оборудования. Даны результаты исследования работы погружного вихревого расходомера на волокнистой суспензии с различной концентрацией, степенью помола и температурой.

Ключевые слова: вихревые расходомеры, тело обтекания, волокнистая суспензия, технологические испытания.

\section{Введение}

В целлюлозно-бумажной промышленности при выработке готовой продукции крайне важен учет холодной и горячей воды, а также различных технологических жидкостей, участвующих в производстве, в том числе древесной массы и волокнистой суспензии.

Перспективными приборами для измерения расхода волокнистой суспензии в целлюлознобумажном производстве (ЦБП) являются погружные вихревые расходомеры с приемникомпреобразователем вихревых колебаний (ППВК). Являясь частью технологического трубопровода, т.е. технологическим оборудованием, они одновременно выполняют функцию измерения расхода воды или волокнистой суспензии [1].

Данные приборы изучались рядом исследователей и рассчитывались на работу в чистой воде либо на волокнистой суспензии с концентрацией до 1,5-2\%. Результаты исследований показали, что при данных концентрациях погружные вихревые расходомеры могут одинаково успешно использоваться для измерения расхода как холодной, горячей воды, так и суспензий без каких-либо принципиальных отличий в измерительном тракте прибора.

Современные процессы производства различных видов бумаги все чаще используют суспензии с более высокой концентрацией волокон (3-6\%) зависящей от стадии производства и применяемого оборудования. При данных концентрациях суспензии у вихревых расходомеров резко снижается достоверность измерения, что сужает область их использования в той или иной технологической операции ЦБП.

Для расширения области использования данного оборудования путем повышения достоверности его показаний необходимо исследовать работу вихревых расходомеров на реальных рабочих жидкостях и выработать меры конструктивного и технологического порядка, допускающие использование данного оборудования в широком диапазоне концентрации волокон.

Основными задачами исследования являются: разработка оборудования для имитационных испытаний кондуктометрических погружных вихревых расходомеров, которое позволит учитывать как гидродинамику работающего в трубопроводе расходомера, так и свойства реальной рабочей среды (концентрация,

Лурье Михаил Семенович - профессор кафедры электротехники, доктор технических наук, тел.: (391-2) 27-57-67, e-mail: m_o_1@rambler.ru Фролов Александр Сергеевич - старший преподаватель кафедры электротехники, тел.: (391-2) 27-57-67, e-mail: Frolov-a84@mail.ru степень помола, температура); исследование работы погружного вихревого расходомера на волокнистой суспензии с различной концентрацией, степенью помола и температурой. На рисунке 1 показано оборудование для имитационных испытаний погружных вихревых расходомеров.

\footnotetext{
* Автор, с которым следует вести переписку.
} 


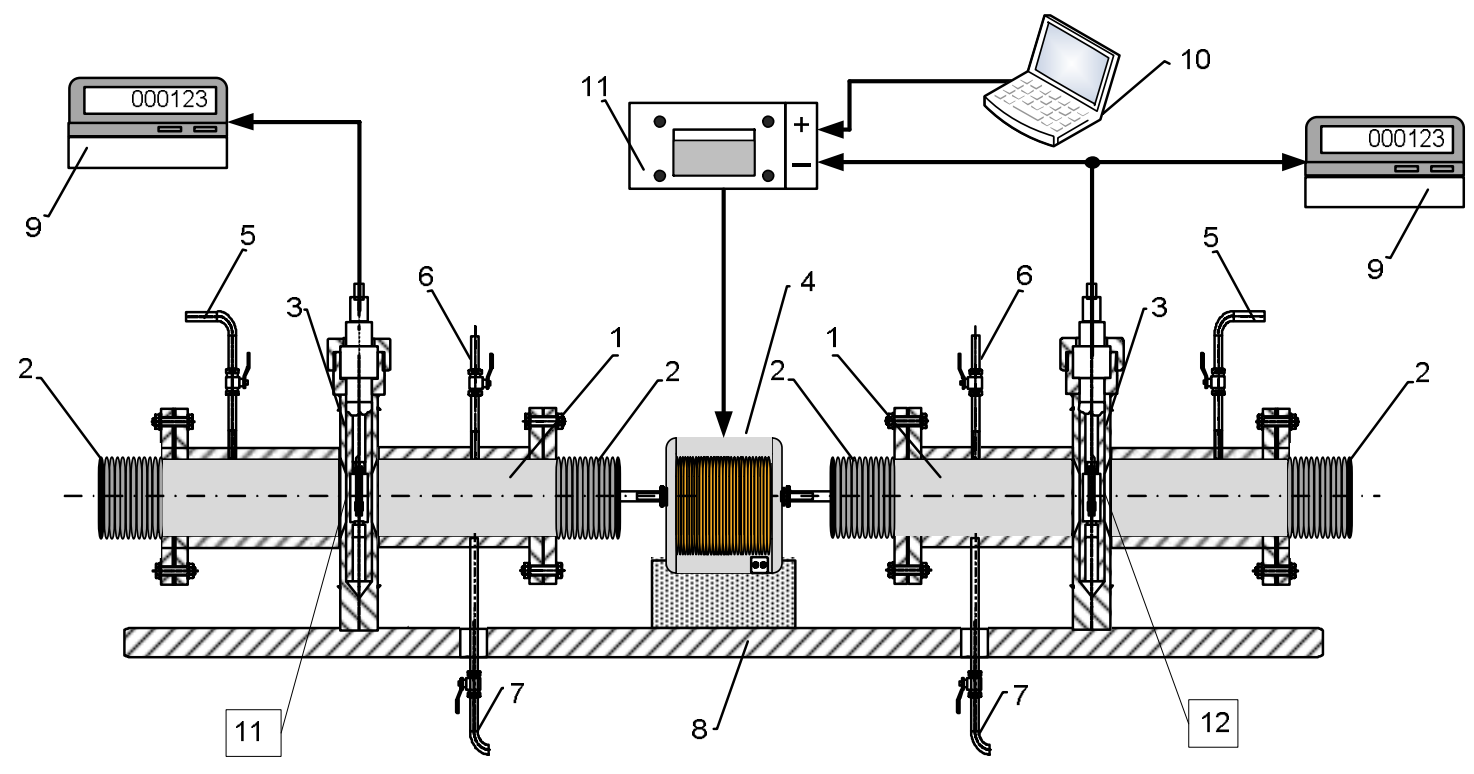

Рис. 1. Оборудование для испытаний погружных вихревых расходомеров:

1 - камера; 2 - сильфон; 3 - перегородка; 4 - электродинамический привод; 5 - входной патрубок;

6 - патрубок для выпуска воздуха; 7 - сливной патрубок; 8 - станина; 9 - счетчик импульсов с дисплеем;

10 - ноутбук для задания входного сигнала; 11 - испытуемый прибор; 12 - эталонный прибор

В основе работы данного оборудования лежит допущение о том, что для получения электрического сигнала определенной формы с ППВК необходимо воздействовать на него перепадом давления также строго определенной формы. Если на выходе ППВК будет формироваться сигнал, близкий к реально действующему сигналу в приборе на заданном расходе, то и гидродинамический режим работы канала обратной связи (КОС) будет близок к реально существующему [2].

Оборудование состоит из двух одинаковых камер (1), на мембраны которых действует электродинамический привод (4). В одной камере залита вода и вставлен эталонный прибор (12), а в другой залита волокнистая суспензия с известными параметрами (концентрация, степень помола, температура) и вставлен испытуемый прибор (11). Камера с водой охвачена обратной связью для правильного воспроизведения пульсаций давления.

Под их действием волокнистая суспензия совершает знакопеременный переток в КОС и периодически изгибает чувствительный элемент ППВК (гибкий электрод). При прогибе чувствительного элемента изменяется межэлектродное сопротивление ППВК, которое электронной схемой преобразуется в выходной сигнал.

В процессе испытания на выходе расходомеров формируется определенное количество импульсов, пропорциональное некоторому объему жидкости, прошедшему через приборы. Их количество фиксируется соответствующими счетчиками импульсов с дисплеем (9). Сравнивая показания счетчиков, можно судить о погрешности измерения на данном испытательном расходе.

Большим преимуществом данного оборудования является малый объем испытуемой жидкости - 0,2 л.

Для того чтобы описать движение жидкости в герметичных камерах, нужно рассмотреть протекание жидкости через КОС расходомера. Используя метод «контрольного объема», получим уравнение для средней скорости движения суспензии в КОС [3]:

$$
\frac{d V_{K O C}}{d t}=\frac{1}{a_{H} m_{K}}\left(S_{K O C} \cdot \Delta P-F_{T}\right)=\frac{S_{K O C}}{a_{H} m_{K}}\left(f_{1}(t)-\operatorname{sign}\left(V_{K O C}\right) \xi_{C У M}(\operatorname{Re}) \rho \frac{V_{K O C}^{2}}{2}\right),
$$

где $V_{\text {КОС }}$ - скорость движения жидкости в КОС, м/с; $a_{И}$ - корректирующий коэффициент, учитывающий, что скорость потока изменяется по сечению. Для ламинарного течения $a_{h}=1,33$, а для турбулентного $a_{U}=1,03 \div 1,04 ; m_{K}-$ масса жидкости в контрольном объеме, кг; $\Delta P$ - перепад давления, Па; $f_{l}(t)$ - зависимость перепада давления $\triangle P$ от времени; $F_{T}=F_{K о C}+F_{C}-$ силы сопротивления движению жидкости; 
$F_{K O C}=\zeta_{C У M}(\operatorname{Re}) S \rho \frac{V_{K O C}^{2}}{2}-$ сила гидродинамического сопротивления КОС; $\zeta_{C У M}(\operatorname{Re})-$ коэффициент гидродинамического сопротивления КОС (зависящий от числа Рейнольдса); $S_{K O C}$ - площадь поперечного сечения КОС, м $^{2} ; \rho$ - плотность жидкости, кг $/ \mathrm{M}^{3} ; F_{T}$ - сила, обусловленная сопротивлением растягивания сильфонов.

В оборудование включен линейный электродинамический привод, создающий силу $F_{\text {эм}}$, которая будет действовать на мембрану камеры

$$
F_{\ni M}=B L I
$$

где $B$ - индукция магнитного поля в зазоре электромагнита привода, Тл; $L$ - длина проводника катушки, м; I - ток в катушке электромагнита, А.

Для имитационной модели блока электропривода инерционные свойства катушки привода можно задать в виде передаточной функции первого порядка

$$
W_{\text {ЭПР }}(p)=\frac{K}{T p+1}
$$

при $K=B L / R_{K}$, а $T=L_{K} / R_{K}$,

где $L_{K}-$ индуктивность катушки, Гн; $R_{K}$ - сопротивление катушки, Ом.

Поскольку в конструкции камеры два сильфона, сила их сопротивления движению электропривода $F_{C}$ будет

$$
F_{C}=2 \cdot K_{C} \cdot l_{\text {nep }}=2 \cdot \frac{K_{C}}{S_{C}} \cdot \int S_{K O C} \cdot V_{K O C} d t
$$

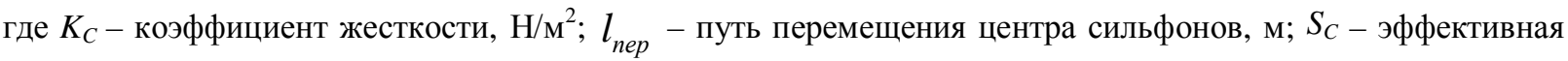
площадь сечения сильфона, м $^{2}$.

Учтем силу сопротивления мембраны (4) в ранее найденном выражении (1) и окончательно получим:

$$
\frac{d V_{K O C}}{d t}=\frac{1}{a_{H} m_{K}}\left(S_{K O C} \cdot \Delta P-F_{T}-2 F_{C}\right)=\frac{S_{K O C}}{a_{H} m_{K}}\left(f(t)-\operatorname{sign}\left(V_{K O C}\right) \xi_{C У M}(\operatorname{Re}) \rho \frac{V_{K O C}^{2}}{2}-2 \frac{K_{C}}{S_{C}} \int V_{K O C} \cdot d t\right) .
$$

Для оптимизации конструктивных и метрологических параметров оборудования была использована имитационная модель оборудования в среде Simulink программы Matlab.

\section{Экспериментальная часть}

На разработанном оборудовании (рис. 1) были проведены исследования влияния технологических параметров волокнистой суспензии на погрешность вихревых расходомеров (ПВР).

В результате испытаний погружных вихревых расходомеров были получены зависимости погрешности измерений ПВР от: скорости течения суспензии (расхода) при постоянной концентрации (рис. 2); степени помола и концентрации суспензии (рис. 3); температуры при заданной концентрации (рис. 4). В качестве исследуемых жидкостей использовались бисульфитная небеленая целлюлоза и вода. Концентрация волокнистой суспензии изменялась от 1,5 до $6 \%$.

Из графика видно, что на малых расходах расходомер имеет наибольшую погрешность, поэтому в дальнейшем исследуем работу прибора на минимальном расходе $\left(\mathrm{Q}_{\text {мин }}\right)$.

Из рисунка 3 видно, что степень помола волокна мало влияет на погрешность ПВР.

На рисунке 4 показано, что при концентрации более $2 \%$ погрешность значительно возрастает, а с ростом температуры погрешность снижается во всем диапазоне исследуемых концентраций. 


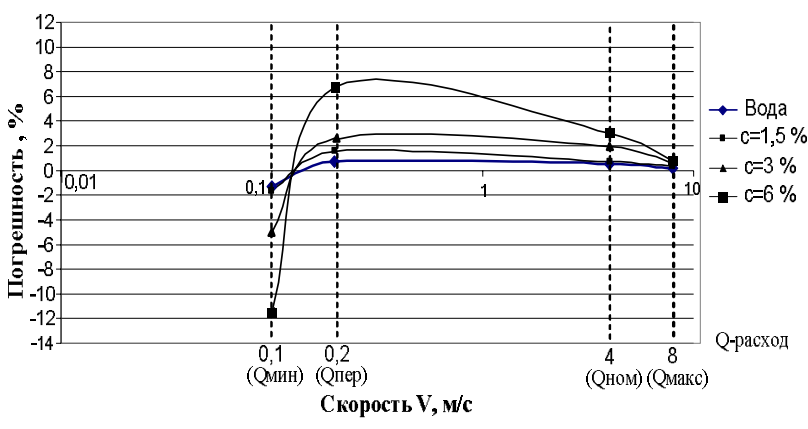

Рис. 2. Зависимость погрешности ПВР от расхода и концентрации суспензии при степени помола $20^{\circ}$ (при $\mathrm{t}=20^{\circ} \mathrm{C}$ )

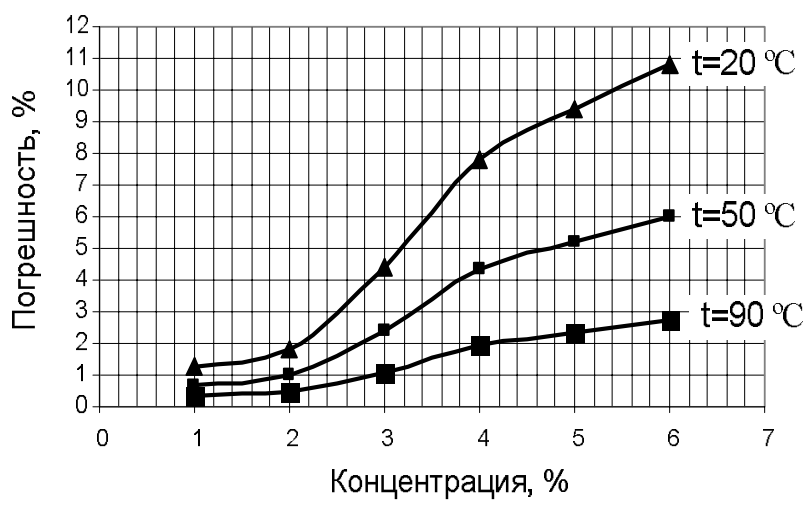

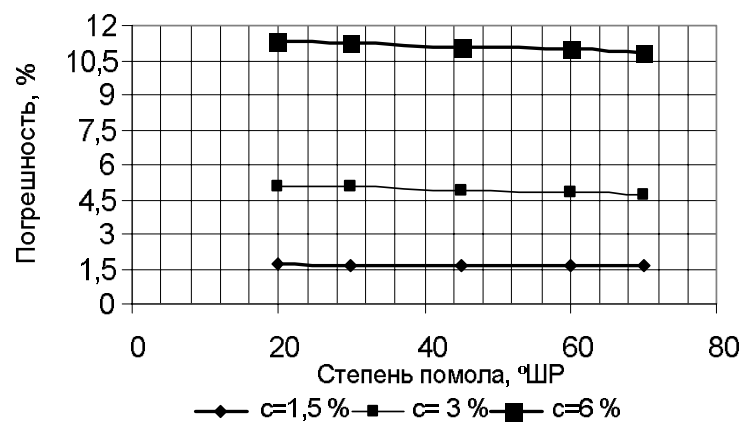

Рис. 3. Зависимость погрешности ПВР от концентрации суспензии со степенью помола 20-70 ${ }^{\circ}$ ШР (при $\mathrm{t}=20^{\circ} \mathrm{C}$ )

Рис. 4. Погрешность ПВР в зависимости от температуры и концентрации суспензии со степенью помола $70{ }^{\circ} Ш Р$

\section{Обсуждение результатов}

Из экспериментальных исследований следует, что большая погрешность возникает на минимальном расходе и в значительной степени зависит от концентрации. Рост погрешности с ростом концентрации объясняется некоторым снижением коэффициента сопротивления гибкого электрода и влиянием флокул, образующихся при малых скоростях течения, которые могут оказывать существенное влияние на движение электрода при малых амплитудах его колебания.

Степень помола слабо влияет на погрешность измерения, а некоторое уменьшение погрешности связано с уменьшением вязкости суспензии при увеличении степени помола волокна.

Повышение температуры суспензии с 20 до $90{ }^{\circ} \mathrm{C}$ приводит к снижению погрешности в 4 раза во всем диапазоне исследуемых концентраций. Данное явление связано с тем, что с ростом температуры вязкость суспензии уменьшается.

\section{Выводы}

1. Разработанное оборудование позволяет испытывать приборы, рассчитанные на условный диаметр 80-1200 мм на волокнистой суспензии с концентрацией до 6\% любой степени помола и температурой до $95^{\circ} \mathrm{C}$.

2. Наибольшее влияние на работу вихревого расходомера оказывает концентрация волокнистой суспензии.

3. Полученные экспериментальные данные позволяют ввести поправки в показания расходомеров в зависимости от рабочих технологических параметров суспензии и обеспечить достаточную точность измерения.

4. Результаты экспериментальных исследований дают возможность разработать методы аппаратного снижения погрешности путем коррекции измерительной характеристики расходомера. 


\section{Список литературы}

1. Лурье М.С., Лурье О.М. Погружные вихревые расходомеры для целлюлозно-бумажной промышленности // Целлюлоза. Бумага. Картон. 2009. №10. С. 62-66.

2. Лурье М.С., Баранов Ю.С., Фролов А.С. Технологические испытания и поверка погружных вихревых расходомеров для целлюлозно-бумажного производства // Датчики и системы. 2010. №6. С. 42-45.

3. Лурье М.С., Фролов А.С. Оборудование для технологических испытаний погружных вихревых расходомеров и счетчиков волокнистых суспензий // Целлюлоза. Бумага. Картон. 2009. №7. С. 62-65.

Поступило в редакцию 7 ноября 2012 2.

Lurie M.S., Frolov A.S. ${ }^{*}$ MEASURING THE FLOW OF FIBER SUSPENSIONS IN THE PULP AND PAPER INDUSTRY

Siberian State Technological University, pr. Mira, 82, Krasnoyarsk, 660049 (Russia), e-mail: Frolov-a84@mail.ru

In this paper the equipment to measure the flow fiber suspension. A method of testing submersible vortex flowmeters takes into account both the hydrodynamics in a pipeline running meter and properties of the fiber suspension (concentration, degree of grinding, temperature). The mathematical relationships explaining test equipment. Presents the results of research submersible vortex flowmeter for fiber suspension with different concentrations, the degree of grinding and temperature.

Keywords: vortex flowmeters, flow around the body, fiber suspension, technological tests

\section{References}

1. Lur'e M.S., Lur'e O.M. Tselliuloza. Bumaga. Karton, 2009, no. 10, pp. 62-66. (in Russ.).

2. Lur'e M.S., Baranov Iu.S., Frolov A.S. Datchiki i sistemy, 2010, no. 6, pp. 42-45. (in Russ.).

3. Lur'e M.S., Frolov A.S. Tselliuloza. Bumaga. Karton, 2009, no. 7, pp. 62-65. (in Russ.).

Received November 7, 2013

\footnotetext{
"Corresponding author.
} 
